\title{
Application of Formative Evaluation with Instructor Directional Feedback to Improve Students Learning Outcomes on Thermodynamics Subject
}

\author{
Ambiyar \\ Faculty of Engineering, State University of Padang \\ Padang, INDONESIA \\ ambiyar@ymail.com
}

\begin{abstract}
The purpose of this research is to show the result of formative assessment application to improve students learning outcomes in Thermodynamics Major, Department of Mechanical Engineering Education, Faculty of Engineering, State University of Padang. The type of research is action research. The results are: (1) the first cycle, the learning activities has not been successful because the percentage of students who pass the passing grade is only $56 \%$ of the total number of students. It called success if at least $75 \%$ student in the class reach a passing grade. It is need for restoration and improvement for the feedback of formative assessment application in the second cycle. (2) The second cycle showed that the learning activities have been successful because the percentage of students who have reached the complete mastery learning is $85.3 \%$ of the total number of students. Therefore, the study was discontinued in the next cycle. This means the application of formative assessment with Instructor Directional Feedback can improve student learning outcomes on thermodynamics.
\end{abstract}

Keywords - formative assessment, learning outcomes, thermodynamics subject, feedback.

\section{Introduction}

Globalization era characterized by the development in science and technology. Technology has very important role and must be controlled properly. Mastery of technology can be reached through the good mastery of science. Therefore, technology causes higher levels of dependence on science. Physics is a part of science. Good mastery of physics would have meaningful contribute to master the technology. The question is, how is the relationship between the Mechanical Engineering and Physics? What are the parts of the Mechanical Engineering? How is the learning outcomes of students in department of education of Thermodynamics Mechanical Engineering? The answer the first question is described: Mechanical Engineering is a branch of science, because it deals with the study of the physical symptoms, but most people associate with mathematical mechanics and the others thought it as science engineering [1].

Furthermore, there are several courses related to Mechanical Engineering. Mechanical Engineering divided into three materials in accordance with the effect of mode of action, i.e., rigid body mechanics, mechanics of materials, and Fluid Mechanics [1]. Curriculum in the mechanical engineering department for undergraduate programs and diploma program at Faculty of Engineering in State University of Padang, presented in Mechanics of rigid body statics course structure, kinematics and dynamics.
Meanwhile, for the Mechanics of Materials course is presented with the name of Mechanics Strength of Materials. Recently featured in Fluid Mechanics, which discusses the fluid liquid (water, oil, mercury, and others) is addressed the fluid and thermodynamics of gas and vapor.

Then, the learning outcomes in Thermodynamics Mechanical Engineering for undergraduate student from July to December 2011 were thirty percent (30\%) obtain sufficient value $(\mathrm{C})$ and in the middle of January to June 2012 gained sufficient value $(\mathrm{C})$ by $50 \%$ (Source : Department of Mechanical Engineering Faculty of Engineering). This means that the mastery level of Thermodynamics Mechanical Engineering students need to be improved. Symptoms of low student learning outcomes in the areas of Thermodynamic studies is a challenge for lecturers and decision makers in education to find alternative solutions to the problem, because they have strategic role of thermodynamics in physics or technological advances.

Assessment has important role in the teaching system, and an integral part of the evaluation system of teaching. There are other evaluations used by faculty in the learning process beside of summative assessment that is the formative assessment. This evaluation can be used by teachers in the learning process to discover the difficulties faced by students in mastering the learning material. This evaluation emphasizes the need for feedback. Gastel [2] says:

".....the best learning, however, they also need feedback along the way-that is, formative evaluation can be included in the course through the measure as following: providing study question (and correcting students providing responses or answers, making available computer programs for use in self-assessment, distributing previous terms of examination or making them available in the library, meeting with students to discuss their performance, and giving practice test...”.

Based on the opinion from [2], in order to get the best learning outcomes of students, it need to be given a formative evaluation for checking the response of the students, after that, it can be conducted feedback by holding discussions with the student, and finally give the test again.

Based on the studies conducted the result indicated that formative evaluation is not in accordance with its function. Evaluation is carried out only two times that are midterms 
and the semester. The test is used as a measuring tool in the midterm in the form of essay and only corrected as right or and wrong answer. Students only know the score that obtained after the test without knowing the material which cannot be answered correctly. Thus the student feedback received only a score.

Slameto [3], quoting the opinion of Roper, distinguish formative evaluation feedback into five levels: level 1 there is no feedback, level 2 there is a right or wrong information which is known as KR (knowledge of results), level 3 there is feedback of information that coupled with one of the correct answers are known as KCR, level 4 there is feedback $\mathrm{KCR}$ plus explanations, and at a rate of five existing $\mathrm{KCR}$ feedback plus additional teaching. The reality on the class, the feedback from the new formative evaluation conducted at the level of 3 , has not reached the level 4 and 5 in the form of the presence of additional teaching or discussion with the students to discuss about weaknesses or difficulties encountered in the student taking the test given to them. This is an issue that needs to find a solution, because it has an impact on student learning outcomes.

Another part of the consideration to students is the learning process is more centered to student (student learning center). Discussion is an active student learning. Students can express their ideas and listen to the ideas of his friend. Students can check the substance and logic of his ideas with peers, and were able to use their own logic. Students are aware that they know and there is nothing they do not know and is ready to recognize the limitations of his knowledge. Therefore, students should be actively thinking together and exchange ideas, and share knowledge about the subject matter. Thus there will be a good interaction between students. In this study is used discussion with directives

The purpose of this study is to prove that the application of formative evaluation will improve learning outcomes of students in department of Thermodynamics Mechanical Engineering Education, Faculty of Engineering, State University of Padang.

In the field of education recognized summative evaluation and formative evaluation. Summative evaluation is to indicate the type of evaluation that used at the end of a term, course, or program, for the purpose of grading, certification, evaluation of progress, or research [4]. So given a summative evaluation at the end of the course or program with a view to hierarchy, certification, and evaluation of progress, and meanwhile research. Formative evaluation is a judgment of strength and weakness of the instruction in its developing stages, for the purposes of revising the instruction to improve its effectiveness and appeal. Next Seels and Glasgow said: formative evaluation is used to identifying deficiencies in the materials while they are being "formed" in order to correct deficiencies. So the formative evaluation is used to identify the strengths and weaknesses of the learning material with the intention of fixing and revising it [5].

Table 1. Differences between Formative and Summative Evaluation

\begin{tabular}{ll}
\hline Formative Evaluation & Summative Evaluation \\
\hline $\begin{array}{l}\text { 1. Especially for } \\
\text { prospective }\end{array}$ & $\begin{array}{l}\text { 1. Especially for } \\
\text { retrospective }\end{array}$ \\
$\begin{array}{l}\text { 2. Analyze the strengths } \\
\text { and weaknesses for } \\
\text { improvement }\end{array}$ & $\begin{array}{l}\text { 2. Documenting learning } \\
\text { achievement }\end{array}$ \\
$\begin{array}{l}\text { 3. Develop the habit } \\
\begin{array}{l}\text { 4. Direction of } \\
\text { professional } \\
\text { development }\end{array}\end{array}$ & $\begin{array}{l}\text { 4. Show results } \\
\text { 5. Evidence of the formative }\end{array}$
\end{tabular}

\section{Opportunity to reflect} on the previous result

Source : http;//www.vtep.edu/cetal/portofolio/develop.htm

Formative evaluation gives feedback. What is that feedback? Heinich, et.al said [6]: not only feedback that help us to ensure whether the instruction has been successful or not, but also tends to take the burden off from the student and place it where it more appropriately belongs-on the sender of the message. From the Heinich et.al [6] opinion it can be concluded that the feedback was used: (1) to ensure whether the teaching has been successful, (2) get students responsibility in learning, and (3) placing students in more appropriate in teacher assessment. Teachers usually blame students when teaching is not successful. The real problem maybe because teaching is not designed appropriately or well presented. Anglin [7] says that support learning by providing feedback information to learners about their performance, either confirming successful performance. So the feedback relates to information about student performance, in terms of success and failure.

Instructor-directive discussion has the intent or purpose. Some best purposes can be done by instructordirective discussion that are to motivate participation, provide for interaction, recognize contribution, define terms, clarify the content and objectives, and identify the Assumption [8]. Based on the opinions expressed by McBeath [8] is seen that the discussion of this pattern is very useful for students, both in increasing motivation, interaction, contribution, reducing doubts about the topic being studied At the end of the discussion session evaluation. There are several methods that can be used to evaluate the process of discussion of the opinion (point of view) of the students. One evaluation format that is widely used in the discussion is a post- meeting reaction (PMR) [8].

\section{Methods}

The subject of this research is the students of engineering department who take courses in thermodynamics from July to December 2012. The form of research is action research with a qualitative approach. The study design will be used is the design with the spiral model (cycle). In general, each cycle consist of: (a) planning, (b) action, (c) observation, and (d) reflection [9] [10]. Data collected in this study using a test, PMR format. Data were analyzed with descriptive analysis techniques. 


\section{Results and Discussion}

The research results in the first cycle, that is:

1. The number of students enrolled from July to December is 35 students, while 34 students participating in learning and only one person is absent, because the student is in attempting to be a cop.

2. The increasing boldness of students in asking questions about the material that has not been understood.

3. Increased student's activity in the learning process.

4. Students shown seriousness in learning and doing their jobs.

5. Mastery learning of students is $19 \%$ and the percentage of students who have not completed $44 \%$.

6. Classical completeness has not been reached which need for improvement individually.

From the above analysis it can be seen that the learning activities undertaken have not succeeded because the percentage of students who pass the study reached $56 \%$ of the total number of students. A class is called success if it reaches a passing grade of at least $75 \%$ of the number of students in the class.

Learning activities that conducted, have not been successful. This showed that of the number of passing grade is still below $75 \%$. The causes of the failure of the first cycle, as follows:

1. Classroom atmosphere not conducive, because the majority of students given less attention to the learning materials.

2. There are still students who have not fully active.

3. Giving feedback formative evaluation needs to be improved in order to be perceived by the students.

4. In the learning process there are students who feel bored and ask permission out with a variety of reasons.

5. There are still some students who are shy and afraid to answer questions and ask the things that have not been understood.

It is necessary for restoration and improvement of the application of formative evaluation feedback on learning in the second cycle. In the second cycle will be made to repair and improvements, both in the improvement of the media of learning, as well as an increase in motivation or opportunity for students to express opinions, ask questions, and answer questions. This is supported by the provision of additional value for students who participate actively and creatively in learning. Similarly, during the discussion of the material interspersed with humorous jokes to make the class more enjoyable atmosphere.

The research results in cycle 2 , namely:

1. The increasing boldness in asking students about the material that has not been understood.

2. Increased student's activity in the learning process.

3. Students have shown seriousness in learning and doing their jobs.

4. The number of students who completed the study, namely 29 and student presentations unresolved is $14.7 \%$.

5. Classical completeness has been reached where there are students who need improvement individually.

From this analysis it can be seen that the learning activities have been successful because the percentage of students who have achieved complete mastery learning is $85.3 \%$ of the total number of students.

Based on the data obtained from the second cycle it can be seen that student learning outcomes increasing significantly and have met the desired target, and $85.3 \%$ of the students have reached the KKM (Minimum Criteria for completeness) is set, this means that the classical completeness student learning outcomes have been achieved.

Research subjects who had taken on Thermodynamics subject from July-December in academic year 2012/2013 using formative evaluation feedback patterns instructordirective. The application of formative evaluation feedback pattern directed instructor for 6 weeks was conducted in two cycles. Each cycle of meetings conducted 3 times and each end of the cycle is given an evaluation test to see the learning outcomes achieved by students.

The first meeting in the first cycle held on Thursday, October $4^{\text {th }}, 2012$. In the first meeting of the implementation of the action, lecturer run all the plans that have been prepared in the event of Learning Unit. Learning lasts 120 minutes. At this first meeting the lecturer explained about perfect gases.

The second meeting in the second cycle held on Thursday, October 11, 2012. Learning is lasted for 120 minutes. In this class 2 lecturers provide formative evaluation with perfectly gas subject used for formative evaluation essay test. The purpose of formative evaluation is to examine the difficulties and errors experienced by students. Time used to test is 60 minutes. After the student answer sheets are collected then the answer sheets were observed and followed a question and answer with students about the difficulty in answering test questions. Based on the observation of answers sheet and information given about the difficulty answering test questions, the next step is to provide feedback with the instructor-directive pattern, so that students can find the mistakes and at the same time be able to understand and apply the formulas contained in the material a perfect gas.

The third meeting in the first cycle held on Thursday, October $18^{\text {th }}, 2012$. In the implementation of the action in cycle 1 , the lecturer gives the test again on a perfect gas to measure the level of achievement of learning outcomes of students with formative evaluation of the implementation of feedback directed pattern instructor. From a given test and answer sheets of students who have been examined and assessed that the test results obtained by the learning activities undertaken have not been successful because the percentage of students who pass the study reached $56 \%$ of the total number of students. A class is called success if it reaches a passing grade of at least $80 \%$ of the number of students in the classroom. Because of the study does not meet the minimum criteria expected then learning continued in the second cycle.

In the second cycle at the first meeting held on Thursday, October $25^{\text {th }}, 2012$. In the first meeting of the implementation of the action, lecturer runs all the plans that have been prepared in the event of Learning Unit. The learning process lasts for 120 minutes. At this meeting the lecturer explains the material non-flow processes and applications. Lecturer gives examples about the application 
process and subsequent non-flow, then gives exercises to work with students. This task is guided by the lecturer in the solution. At the end of the study concluded that teaching materials have been studied.

The second meeting, in this cycle held on November, $1^{\text {st }}, 2012$. Learning is lasted for 100 minutes according to the weight of credits for courses of Thermodynamics, which are 2 credits. During the 60 minutes used by lecturers to provide formative evaluation to test essays. The purpose of this formative evaluation is for knowing difficulties and errors experienced by students to answer the test. After the student finished, sheets are collected in answering test, then the answer sheets were observed and followed a question and answer with students about the difficulty in answering test questions. From the observation sheet answers and information given about the difficulty answering test questions, then the next step to provide feedback to the instructor directed pattern for 40 minutes, so that students can find the mistakes and at the same time be able to understand and apply the formulas that exist in non- flow processes and materials in the application.

The third meeting in this cycle held on Thursday November $8^{\text {th }}, 2012$. At this meeting, the lecturer gives the test again on a non flow process and its application to measure the level of achievement of learning outcomes of students with formative evaluation of the implementation of feedback directed pattern instructor. From a given test and answer sheets of students who have been examined and assessed that the test results obtained by the learning activities undertaken have been successful because the percentage of students who pass the study has reached 86.3 $\%$ of the total number of students. A class is called success if it reaches a passing grade of at least $80 \%$ of the number of students in the classroom. Because of the minimum completeness is reached then we don't continue the cycle again. In another words, the cycle stops in cycle 2 .

Learning outcomes of thermodynamics that have been achieved with the application of student feedback formative evaluation pattern directed instructor for two cycles can be seen in the picture below.

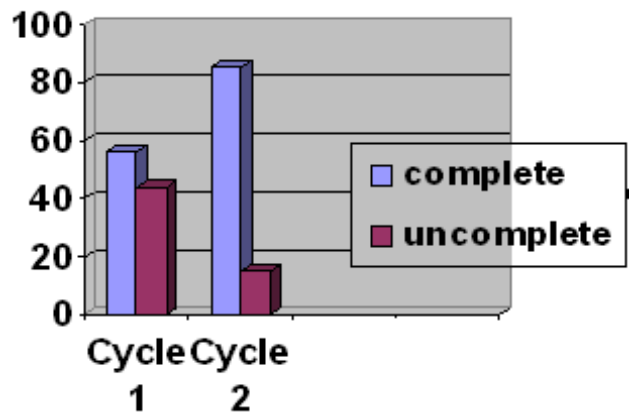

Fig. 1. Bar Chart of Student Learning Outcomes in Cycle I and Cycle II

Further discussion per cycles performed during the learning process. More detail can be seen in the discussion below per cycle.

\section{Cycle I}

At the beginning of the first cycle before applying formative evaluation feedback patterns instructor directed, student learning outcomes have not shown an increase in activity among students and have not had the courage to express their opinions because of frightened of being wrong and also nervous because the students are not familiar with the method. Students need to be aware that they are known and some of them do not know and another is ready with limited knowledge. Therefore, students should be actively thinking together and exchange ideas and share knowledge about the subject matter.

But after being given the understanding and explained the purpose and benefits of formative evaluation feedback applied to the pattern instructor directed, some students began to show interest. Students have realized the benefit or use of feedback and discussion. This is disclosed in accordance with the by Heinich [6] that feedback is useful to place the student in a more appropriate in the assessment of lecturers and asked responsibilities in learning. Similarly, the opinion supports Klient [11] that the purpose of the discussion needs to be explained to the students so as not to pose questions of the students, why they do the discussion?

With the describe meaning, purpose, and benefits of formative evaluation feedback to the instructor directed pattern of discussion, the learning outcomes of students in cycle 1 has not been as expected. Thermodynamics learning outcomes are achieved by only $56 \%$ of students who meet the minimum criterion for completeness, the remaining $44 \%$ have not met the minimum criteria for completeness. According Nitko [12] criteria for success in the study is 80 $\%$ of the students met the classical criteria of minimum completeness. In this study the indicators of success of students declared successful in mastering the material Thermodynamics with values $\geq 70$. This means that students who scored below 70 Thermodynamics expressed have not been successful (completed).

\section{Cycle II}

For completeness (1992) that the pattern of discussions directed instructor can assist students in the learning process and motivation in learning.

Discussions have increased interest in thermodynamics courses, helping students master the material and can ultimately improve learning outcomes. Thus supports the opinion expressed by Gastel [2] that functions in science lessons to develop an interest and enthusiasm, get clarification, help students master, apply, and improve skills in solving problems. Thermodynamics is included instruction in science. Having held discussions, students' skills in solving problems related to the perfect gas or nonflow and application process, of course, can boost learning outcomes.

In general, an increase of student learning outcomes in this cycle has reached the target needed. In the second cycle is $85.3 \%$ of students who achieved the KKM (Minimum Criteria for completeness). .In other words, the targets to be achieved in this study has been achieved, as an indicator of success is classical minimum completeness criteria $\geq 80 \%$.

\section{Conclusion}

After all the research process is conducted until the results obtained, the researchers concluded the following : 
1. The application of formative evaluation feedback with instructor-directed pattern can improve student learning motivation in the classroom. It is characterized by increasingly quality of activities and students' skills in solving problems given by lecturers, increasing communication and cooperation of students and student learning outcomes obtained. Such improvements include: (a) increased student cooperation and mutual assistance among students to solve problems in the learning process (b) Increasing compactness between students (c) increased student involvement and activeness in the process learning. In general, increasing the quality of the student learning process looks at the emergence of the excitement of the students in the following study.

2. The application of formative evaluation feedback with instructor pattern directed at the subject of Perfect Gas and Non- Flow Process has given new nuances in Mechanical Engineering so that learning is more effective. This is proven by the significant changes to the mastery learning students. Found on the results of student evaluations conducted the first cycle reached an average value of 65 with a $56 \%$ passing grade , but has reached a 75 second cycle with a passing grade of 85.3 $\%$.

3. With the application of formative evaluation feedback to the pattern directed instructor, students have been mentored by lecturer to understand the difficulties and errors in resolving problems in thermodynamics, especially the subject of Perfect Gas, Process and Application of Non Flow has gained ease of teaching students to understand the material presented, making it more effective and efficient. As a facilitator and a good observer and lecturer successfully prosecuted stimulate reasoning capabilities are more successful students and instill positive attitudes to students.

\section{References}

[1]. Beer, Ferdinand P dan E. Russel Johnston, Jr. 2007. Mechanics for Engineer. New York: Mc-Graw Hill Book Company, Inc.

[2]. Gastel, Barbara. 1991. Teaching Science. Canada: The Oryx Press.

[3]. Slameto. 1988. Evaluasi Pendidikan. Jakarta: Bina Aksara.

[4]. Bloom, Benyamin S. et.al. 1971. Handbook on Formative and Sumative Evaluation of Student Learning. United State of America: Mc-Graw-Hill, Inc.

[5]. Tessmer, Martin. 1995. Planning and Conducting Formative Evaluation. London: Kogan Page Limited.

[6]. Heinich, Robert et.al. 1996. Instructional Media and Technologies for Learning. New Yersey: Prentice-Hall, Inc.

[7]. Anglin, Gary J. 1995. Instructional Technology, Past, Present, Future. Colorado: Libraries Unlimited, Inc.

[8]. McBeath, Ron. 1992. Instructing and Evaluating in Higher Education. New Yersey: Educational Technology Publication Inc., Englewood Cliff.
[9]. Depdiknas. 1999. Penelitian Tindakan (Action Research) Bahan Penelitian. Jakarta: Proyek Peningkatan SMU.hnologists. New York: John Willey \& Son, Inc.

[10]. Wardani, IGAK. 2007. Penelitian Tindakan Kelas. Jakarta: Universitas Terbuka.

[11]. Klien, Roy. 1996. Effective Teaching Strategies, Lesson from Research and Practice. Australia: Social Science Press.

[12]. Nitko, Anthony. J. 1996. Educational Assessment of Studies. New Yersey: Prentice-Hall, Inc. 